\title{
MISTRAL MISTRAL
}

Journal of Latin American Women's

Intellectual \& Cultural History

Historia Feminista de la literatura argentina. En la intemperia: poéticas de la fragilidad y la revuelta coordinado por Laura Antonella Arnés, Lucía María De Leone y María José Punte (reseña)

Carolina Ramallo, Universidad de Buenos Aires

To cite this review: Carolina Ramallo. 2021. Reseña de Historia Feminista de la literatura argentina. En la intemperia: poéticas de la fragilidad y la revuelta coordinado por Laura Arnés, Antonella, Lucía María De Leone y María José Punte. Mistral: Journal of Latin American Women's Intellectual \& Cultural History 1 (2): 115-117, https://doi.org/10.21827/mistral.2.38036 
Laura Antonella Arnés, Lucía María De Leone y María José Punte (coords.), Historia Feminista de la literatura argentina. En la intemperie: poéticas de la fragilidad y la revuelta. Villa María (Córdoba): EDUVIM, 2020. 592 págs. ISBN 978-987-699-622-8

Es necesario reescribir. Reescribir para volver a contarnos y ver a cuántos perdimos, cuántos quedamos. Reescribir para, por un ratito, el del tiempo del relato, cambiar la historia, pero que, también, al terminar el cuento, al haber vuelto a contar, haya cambiado la historia. Eso es lo que hace la Historia feminista de la literatura argentina (dirigida por Laura Arnés, Nora Domínguez y María José Punte). Nos viene a contar que es posible reescribir y cambiar la historia. Nada más y nada menos que en medio de una situación extremadamente perturbadora como la de la pandemia por Covid que azota el mundo: no podría haber escena mejor para repensar las relaciones de dominación, exclusión y selección de las vidas - cuáles son las vidas vivibles, cuáles las legibles-que esta; no podría haber escena más justa ni más necesaria para reescribirlo todo.

El tomo En la intemperie. Poéticas de la fragilidad y la revuelta (coordinado por Laura Arnés, Lucía De Leone y María José Punte) produce un recorrido desde la última década del siglo XX hasta el presente (o, en realidad, hasta justo antes de este presente distópico pandémico en el que estamos) a partir de la exploración de estas tres categorías tan productivas: la intemperie, la fragilidad y la revuelta, y especifica, de este modo, lo que es la propuesta de todo el proyecto intelectual: producir una nueva mirada, una nueva forma de leer la historia de la literatura argentina, no para sancionar un nuevo canon, sino para rever lo ya visto con nuevos ojos, para ejercitar otro modo de leer, para releer y reescribir esa misma historia.

En la sección "Alianzas feministas", Anahí Mallol explora la potencia de lo performativo, de poner el cuerpo, a través de su lectura de "Zapatos rojos". Andi Nachón estudia la relación de la poesía y las luchas por el aborto, especialmente en la poesía que teje una red de mujeres. Cecilia Palmeiro ofrece un mapa de la insurgencia vanguardista y feminista de Belleza y Felicidad, con su ruptura de la autonomía literaria, sus apuestas micropolíticas y la articulación con el movimiento Ni una menos y el feminismo villero. Claudia Kozak, por su parte, analiza las artes contemporáneas como desestabilización y el uso de la tecnología (campo históricamente masculino) en la participación comunitaria y las artes participativas. Y, finalmente, en "Nube Loca mata al Buda -formas de vencer la fuerza de gravedad del nombre" vane guerra presenta una problematización del nombre, de lo individual, y una apuesta por el canto polifónico como épica de los poetas.

En el "Deshechos neoliberales", Gabriel Giorgi estudia las escrituras performáticas del odio como reformulación de lo público, las pedagogías públicas con la puesta de lo femenino en el centro de las disputas y la organización de nuevas formas de decir y de hacer. Flor Minici presenta una exploración de la representación de los monstruos, lo indecible, el trabajo y el cuidado en el contexto del neoliberalismo y su crisis. Isabel Quintana propone que la deconstrucción apuesta por el impedimento de la clausura del pensamiento en narradoras, artistas y cineastas, sin dejar de atender al resto como lo expuesto a desaparecer, pero también como resistencia vital. Inés Kreplak hace un interesantísimo análisis de las transformaciones en los modos de narrar, representar y leer la violencia contra las mujeres y cuerpos feminizados en relación con el acceso a derechos humanos. En este sentido, abre la puerta al deseo de que ahora comiencen a ser visibles los relatos de hijas e hijos de víctimas de femicidios. Por su parte, Francine 
Masiello explora el modo en que la pregunta por cómo manejar la violencia que nos rodea aparece en la producción cultural de mujeres y propone, también ella, a la literatura como lugar de construcción de otros patrones de significado para la vida.

En "Territorios generizados", Lucía De Leone revisita y reinventa la pampa como un territorio desvirilizado y desheteronormativizado y propone un repertorio visual y literario en relación con la ecocrítica y las ficciones ecológicas. Luego nos encontramos con "Mi conurbanidad" de Alessandra Luna, poema sobre transfeminismo popular. Lo que se pone en evidencia con este poderoso movimiento de resistencia desde la literatura es que corre parejo con una crisis de los géneros (en sus dos sentidos de la palabra en castellano) pero también de los debates y las instituciones. Estas escrituras, como la de gaita nihil en la sección 4, como en numerosas ocasiones la poesía, sacan su poder contestatario del hecho paradójico de que parece no serlo o juega a confundirse con una prosa marginal, reordenada para servir a los poderes de la liberación y la protesta ya que desautomatizan la percepción y hacen advenir la conciencia del futuro.

Esta sección continúa su recorrido con el trabajo de Paula Daniela Bianchi, quien sin dejar de hacer una exploración de los límites y alcances de los conceptos y de las discursividades, recorre la literatura y los debates sobre trata, trabajo sexual y abolicionismo como visibilización de la urgencia. Luego, Tamara Tenenbaum explora la crónica y periodismo narrativo latinoamericanos con voluntad literaria que sin espectacularización ni estetización, postulan una relación con el saber y la verdad. Juana Roggero trabaja la voz de las madres del siglo XXI en una literatura que se hace cargo de pensar el tiempo de la experiencia de la maternidad. Y a continuación, y en continuidad, Carolina Grenoville, trabaja la articulación de la intimidad (de la maternidad, de la casa, del trabajo de cuidado y de los vínculos) con el poder e indica allí una ética de la escritura en su crítica a los modos de vida hegemónicos. Por último, Mónica Szurmuk y Mauro Lazarovich estudian el multilingüismo en las escrituras con escucha hacia la otredad y en los modos en que las lenguas "otras" problematizan las identidades nacionales.

El "Ante la crítica" se abre con el trabajo de Florencia Angilletta a partir de la pregunta ¿qué hacen las mujeres con lo que la letra hace de ellas? Este artículo, como otros del volumen, hace el valioso gesto de preguntarse sobre la propia práctica, por ejemplo, colocando comillas para los conceptos y categorías y explicitando las acciones de organizar e historizar las críticas literarias feministas argentinas. Luego, Julieta Obedman desde su rol de editora estudia un fenómeno relevante para la industria del libro local: la novela escrita, protagonizada y leída por mujeres. Guadalupe Maradei ofrece su recorrido por las Historias de la literatura postdictadura para relevar, describir y analizar los modos de leer (el histórico y el feminista) de la crítica literaria y María Sonia Cristoff estudia la experiencia de escritura de novelas y la literatura como práctica desestabilizante, cuestionadora.

El "Eróticas festivas" comienza con el artículo de Laura A. Arnés que revisa el modo en que la sexualidad como instrumento crítico habilita la reflexión sobre la vida del cuerpo y sus narrativas y construye y propone la categoría "ficciones lesbianas" como un modo de los desvíos imaginarios, sexuales y textuales en la literatura argentina, incluso más allá del especismo, como posibilidad de acción. Paula Jiménez España estudia las mujeres en la gestión de espacios de poesía con una prolija historización desde la década de 1970 hasta la sanción de la interrupción voluntaria del embarazo. Pablo Farneda analiza las escrituras travestis-trans como práctica de sí que producen un modo de vida, nuevas formas de lo visible y lo enunciable, mutaciones culturales y disputa de géneros artísticos y para cerrar este capítulo tenemos "Panfleto" 
de María Moreno, texto que da nombre al libro Panfleto. Erótica y feminismo, con sus 7 puntos perfectos, imposibles de parafrasear.

"Jóvenes insolentes", última sección del tomo, comienza con la historia del ser mujer en el siglo XX para, desde el anacronismo, pensar la poesía actual como reapropiación y afirmación en el artículo de Tamara Kamenszain. Continúa con una sólida historia de la violencia machista, la desigualdad de género y el uso de la categoría "vida" que ofrece Ilona Aczel en relación con la legalización del aborto. A continuación, Mariela Peller trabaja con las escritoras hijas de desaparecidos, asesinados y exiliados, viendo las marcas de género y gestos feministas en la posición política enunciativa, los géneros literarios y los temas. El texto "Dos muchachas" de Julián López es una bellísima escritura autocrítica y autorreflexiva ("con 1[a]s que les escritores solemos traficar lo propio") que termina proponiendo una utopía deseable y realizable: la escritura de un lugar digno para todas y todos. Como cierre, nos encontramos con el estudio de María José Punte sobre la ocupación, uso y reflexión sobre el espacio, la espacialidad y las luchas feministas. Es muy interesante incluir la categoría de espacio para pensar la mirada y la perspectiva (la llamada "perspectiva de género" justamente). El Epílogo de Nora Domínguez nos habla de la literatura como usina de lenguas posibles, hace una historización del periodo buscando ver las reescrituras en el "amontonamiento", las intensificaciones, las acciones, y se pregunta qué puede decir un año. Y es que eso es lo que hace todo el volumen: ver qué puede decir la literatura del periodo, cómo, de qué modo el feminismo y la escritura son deseos de vida.

Es así que intemperie, fragilidad y revuelta permiten organizar los muchos movimientos que el tomo produce: la salida, la problematización de lo público y lo privado, la libertad, la asunción de la fragilidad y la vulnerabilidad como condición de posibilidad de su superación, la organización y la concreción de nuevas formas de lucha, entre otras cosas. Y también hace justicia al giro epistemológico imprescindible para hacer teoría feminista: producir una reflexión que se pregunte por las implicancias de las menciones y de los silencios, del tratamiento representacional y de las articulaciones con acciones políticas en la lucha por el acceso a derechos. Esa pregunta por la implicancia es lo que le da su pertinencia política y lo que hará que cambiemos la historia. 